\title{
Start-ups as drivers of market mobility: an analysis at the region-sector level for The Netherlands
}

\author{
Sierdjan Koster • André van Stel • \\ Mickey Folkeringa
}

Accepted: 1 December 2010/Published online: 2 April 2011

(C) The Author(s) 2011. This article is published with open access at Springerlink.com

\begin{abstract}
Although recent literature suggests that competition among incumbent firms is caused by the entry of new firms, this relationship has not yet been tested directly. In this study a regression model is established in which a direct measure of competition among incumbent firms, the market mobility rate, is explained by start-up rates and control variables. The results show that the effect of start-ups on market mobility varies by sector. There is a strong positive relationship for industry sectors but an insignificant relationship for service sectors. These results suggest differences in the types of entry between sectors and in the roles start-ups play in different sectors.
\end{abstract}

Keywords Start-ups · Incumbent firms · Competition · Market mobility

JEL Classifications $\mathrm{O} 18 \cdot \mathrm{L} 16 \cdot \mathrm{M} 13$

S. Koster $(\square)$

University of Groningen, Groningen, The Netherlands e-mail: sierdjan.koster@rug.nl

A. van Stel · M. Folkeringa EIM Business and Policy Research, Zoetermeer, The Netherlands

A. van Stel

e-mail: ast@eim.nl

M. Folkeringa

e-mail: mfo@eim.nl

\section{Introduction}

This study assesses the impact of start-up rates on market mobility, a measure of competition among incumbent firms. Interactions between new and incumbent firms are important in the process of economic growth, and more knowledge on these interactions is required. This issue fits in a recent strand of empirical research at the regional level (surveyed by Fritsch 2008) which suggests that competition among incumbent firms is caused by (lagged) start-up rates. Contrary to earlier research in this field, this paper employs a direct measure of the level of competition among incumbents, which is called (market) mobility (Cantner and Krüger 2004; Folkeringa et al. 2011). The mobility rate measures to what extent the relative performance of firms (in terms of market shares of individual firms) changes over time. Based on Joseph Schumpeter's theory of creative destruction it can be expected that the mobility rate is positively affected by start-up rates. New firms challenge existing firms by introducing new products and services and market selection will cause the best firms to survive and grow and the least competitive firms to downsize or exit. This should be reflected in a higher value of the market mobility rate.

This study tests this hypothesis by establishing a regression model, at the region-sector level for the Netherlands, in which the market mobility rate is explained by (lagged) start-up rates and control variables. Based on data for 40 regions and five 
sectors over the period 1993-2006, it is found that the effect of start-ups on mobility varies by sector. In particular, there is a strong positive relationship for industry sectors (manufacturing and construction). For the service industry, however, start-up rates and competition are not significantly related. These results suggest there are differences in the types of entry between sectors and in the roles start-ups play in these sectors.

The analysis contributes to existing literature in at least three ways. First, competition among existing firms is measured directly. Earlier studies estimate the impact of new-firm start-up rates on regional economic performance, and decompose the total impact of the new firms in direct and indirect effects. The indirect effects are then assumed to be the result of increased levels of competition among incumbent firms but these levels are not actually measured (Fritsch 2008; Fritsch and Mueller 2004; Van Stel and Suddle 2008). Given the high importance for regional growth ascribed to these indirect effects (Fritsch et al. 2010), it is crucial to start using direct measures of competition when investigating interactions between start-ups and incumbents.

Second, by using a direct measure of competition, the analysis acknowledges the increased importance of small and medium-sized firms in modern economies (Audretsch and Thurik 2001, 2004). While concentration measures, for example the $\mathrm{C} 4$ index or the Herfindahl index, strongly emphasise the importance of the leading (biggest) firms in a market, the market mobility index uses information on relative performance of all firms in a market. A unique database enables hundreds of thousands of firms to be followed over time. Using this comprehensive information, it is possible to capture competition dynamics in all parts of the size distribution, not only the upper tail. Moreover, whereas the $\mathrm{C} 4$ and Herfindahl measures are static in nature, the mobility index captures changes over time. It may be argued this reflects the intensity of competition in a market more accurately (Baldwin and Gorecki 1994).

Third, by combining various data sources the analysis can be done at the level of industries and regions. The scope of analysis is unprecedented. Previous studies focussed mainly on mobility patterns within manufacturing industries and/or within the subset of large or leading firms (Stonebraker 1979; Baldwin and Gorecki 1994; Deutsch and Silber 1995;
Kaminarides and Farahbod 1995; Kato and Honjo 2006; surveyed by Caves 1998). The database used for this paper covers the whole Dutch private sector including all non-agricultural industries. Moreover, as mentioned earlier, for each sector it uses data for all firms, not only the large firms.

The organisation of the paper is as follows. The next section gives a short review of the literature on the relationship between start-ups and the degree of competition between incumbent firms, which in turn should lead to (regional) economic development. As one important contribution of the paper is the use of a direct measure of the outcome of this competition process, viz. the market mobility index, the Sect. 3 discusses how this index is derived and elaborates on its specific characteristics. In the Sect. 4, the database and empirical model are introduced. In the next sections descriptive statistics and estimation results are presented and interpreted, and these sections are followed by the conclusions.

\section{The relationship between start-ups, market mobility, and growth}

Both researchers and policy makers view dynamics in the population of firms as one of the driving forces of economic growth. Various terms have been used to indicate these dynamics. Here, Caves' terminology is followed. He labels the dynamics in the population of firms as "turnover" and he distinguishes between three components of turnover (Caves 1998): the births and deaths of business units (entry and exit), variations in sizes and market shares of continuing units (mobility), and shifts between enterprises in the control of continuing business units (changes in control). This study focuses on the roles that the first two types of turnover play in competition processes. As the term "mobility" is used for different purposes in economic literature, here the term "market mobility" is used to indicate variations in sizes of incumbent firms.

Economies experiencing high levels of turnover (in terms of entry, exit and market mobility) are characterized by many start-up and high-growth firms, but also by many exits and contracting firms. These characteristics reflect a process of fierce competition in which new firms enter the market with new products and services, thus challenging 
incumbent firms to improve their performance. If not, they might be forced to downsize or even exit the market. This challenge is felt by the incumbent firms, and as a result of new-firm entry, competition among incumbent firms increases. The most competitive entrants and incumbents survive, and these businesses grow, whereas the least competitive firms exit the market or are forced to downsize. The result of such a creative destruction process is an ever changing composition of the firm population in an economy where the average quality of the firms is also continuously increasing (as the high-quality firms survive and grow and the low-quality firms decline or exit). This continuing process should result in longterm growth and higher productivity levels. Therefore, turnover may be seen as an indicator of competitiveness of an economy (or industry) and hence economies with higher levels of turnover are expected to achieve higher levels of economic performance (Bosma et al. 2011; Van Stel and Storey 2004).

The theory described above is confirmed by several empirical analyses using micro level data. A standard result in empirical studies on the effect of entries and exits on productivity is that a substantial part of the productivity improvement can be attributed to the entry of new business units with aboveaverage productivity and the exit of units with belowaverage productivity (Fritsch and Mueller 2004). Using employment as performance measure, other studies show that mobility of incumbent firms results in a net increase in total employment at the industry level. For instance, Baldwin (1995) divides Canadian manufacturing firms that survived from 1970 to 1982 into those gaining and those losing employment. The average "gainer" grew by $7.8 \%$ annually whereas the average "loser" shrank by $6.3 \%$. For the German case of continuing firms in the non-agricultural sectors during 1977-1990, Boeri and Cramer (1992) find that employment increased by $6.2 \%$ annually for expanding incumbents whereas the employment of contracting firms shrank $5.8 \%$ annually.

Following the studies at the micro level, a growing literature at the aggregate (typically, regional) level pays attention to the role of business turnover, particularly start-ups, in achieving high rates of economic growth. In particular, special issues of Regional Studies in 2004 (volume 38, issue 8) and Small Business Economics in 2008 (volume 30, issue
1) have been influential in this field. (These special issues have been surveyed by Acs and Storey (2004) and Fritsch (2008).) Recent empirical studies in this field typically tend to use several lags of the start-up rate as determinants of (regional) economic growth and decompose the total effect of start-ups on growth into direct and indirect effects using the Almon lag method (Fritsch and Mueller 2004; Van Stel and Suddle 2008). In this type of study, the indirect effect relates to the effect of increased competition between incumbent firms induced by the new-firm start-ups. However, a limitation of these studies is that the intensity of competition among the incumbents is not actually measured. As a result, the relationship between start-ups and competition among incumbents is not statistically robust. Because the Almon lag studies suggest that the indirect effects may be very large, it is of vital importance to measure the extent of competition among the incumbent firm population, and to measure directly the relationship between start-ups and competition among incumbents in a regression model. As discussed before, this paper attempts to fill these two gaps.

\section{The concept of market mobility and its measurement}

Market mobility indicators measure the extent to which a ranking of a population of firms (in terms of economic performance) changes over time. If the ranking is stable (i.e. the same firms are at the high and low ends of the ranking in two years of comparison), then market mobility is low. If there is a lot of change in the ranking, then market mobility is high. High market mobility rates are assumed to reflect high intensities of competition. As Baldwin and Gorecki (1994) put it: "Mobility indices measure the outcome of the competitive process in terms of transfer of market shares from losers to winners. Much of what happens during the competitive process will be manifested by changes in relative firm position" (p. 95).

Although market mobility rates are clearly valid measures of competition, they are rarely used in empirical work. In part this is because of the large requirements-both in terms of data and in terms of methodology — of measuring mobility. Instead, economists often use concentration measures like 
the $\mathrm{C} 4$ index or the Herfindahl index. However, such measures are indirect measures of competition as they only measure market structure at one point in time (Baldwin and Gorecki 1994; Deutsch and Silber 1995). A possible reason for the widely used concentration measures is that they are easy to calculate and widely available. Baldwin and Gorecki (1994) argue, however, that mobility statistics are more direct measures of the intensity of competition because they "reflect the process that takes place within an industry" (p. 93).

Hence, a first advantage of mobility rates over concentration measures is that they capture changes in market structure, not just a snapshot at a given point in time. A second advantage is that changes in relative firm positions of all firms are used. Concentration measures focus solely on market shares of the leading firms and, therefore, on monopolistic behaviour. As a result, these measures ignore business turnover among the larger part of the firm population. Mobility rates capture changes in market structure considering competition dynamics among all firms in the firm distribution. ${ }^{1}$ This is appropriate, considering the increased importance of small firms in modern economies (Audretsch and Thurik 2001, 2004).

This study uses market mobility indices at the region-sector level for Dutch regions over the period 2000-2006. The indices are computed using Markov chain-based methodology developed by Shorrocks (1978) and Geweke et al. (1986) and recently applied by Cantner and Krüger (2004). An extensive database in which a population of several hundreds of thousands of individual firms can be followed on an annual basis enables computation of the market mobility indices used in this analysis. Based on changes over time in the rankings (in terms of employment size) of the individual firms, competition is measured across sectors and regions. The next subsection describes how the market mobility rates are constructed in practice.

\subsection{Measuring market mobility}

The central issue in measuring market mobility is to capture changes over time in relative firm positions, in terms of economic performance (in this case, relative

\footnotetext{
${ }^{1}$ Kato and Honjo (2006) use an indicator which does use changes in market structure, but which captures only the dynamics of the leading firms.
}

firm size). This entails defining different states which reflect different levels of relative economic performance of individual firms in a specific market. Thus, all firms in each period are distributed over a number of classes ranging from relatively weak to relatively strong economic performance. A high value of the mobility index reflects high differential changes in this distribution for the market concerned. A sophisticated method to measure mobility indices makes use of an estimated transition matrix of a Markov chain. In such a chain, firms are defined to be in different states, e.g. in terms of size. The transition matrix then provides an overview of the transition probabilities of leaving a particular state (i.e. size-class) and entering a different one in a certain time period. The matrix also provides probabilities of staying in the same state for two consecutive moments in time. Theoretical work of Geweke et al. (1986) and Shorrocks (1978) shows how mobility indices can be constructed from the elements (transition probabilities) of the transition matrix.

This study uses the mobility measure $\mathrm{M}_{\mathrm{U}}(\mathrm{P})=$ $n \sum_{i \in I} \pi_{i}\left(1-p_{i i}\right) /(n-1)$, as described by Cantner and Krüger (2004), where $\mathbf{P}$ is the transition matrix, $i$ is an index for the relative size-class, $p$ is a transition probability, $n$ is the number of relative sizeclasses (four, in this case), and $\pi$ is the vector of socalled stationary probabilities. ${ }^{2}$ A detailed description of this index would require discussion of the specifics of Markov chain methodology, which would require too much space (an overview is given by Norris 1998). The intuition is fairly straightforward though: A population of firms in a given market is ranked in four quartiles at two points in time, based on their relative employment size. Transition probabilities from size-class $i$ to size-classes $1-4$ are estimated by counting the proportion of firms moving from sizeclass $i$ to size-classes $1-4$, respectively. The diagonal elements of the transition matrix then provide the probabilities that firms remain in the same (relative) size-class. The mobility measure is constructed in such a way that markets with high values for the diagonal elements (i.e. small probabilities of moving to another size-class), have low market mobility values, and vice versa.

\footnotetext{
$\overline{2}$ In this case, using fractile classes and four groups, the stationary probabilities are 0.25 for each size-class.
} 
Here, only the $\mathrm{M}_{\mathrm{U}}(\mathrm{P})$ mobility measure is used. There are, however, many versions of the mobility measure. Cantner and Krüger (2004) provide an overview of various mobility measures using the Markov chain methodology. Folkeringa et al. (2011) present several other versions of the mobility measures using the same Dutch database as is used in this study. They find that the correlations between the various variants of the mobility measure are very high (approx. 0.9). Therefore, the analysis can be limited to only the $\mathrm{M}_{\mathrm{U}}(\mathrm{P})$ mobility measure.

\subsection{Constructing the market mobility measure}

Folkeringa et al. (2011) discuss a number of empirical choices to be made when computing mobility indices. The mobility rates used in this paper have the following starting points. First, because the relevant market for which mobility indices are to be computed is often a region instead of a nationwide market, data at the establishment level is used instead of at the firm level. Second, as the mobility index is as a measure of competition between incumbent firms (establishments), business turnover at the left tail of the firm size distribution is left out of consideration. Only establishments with five or more workers within the study period are included. Firm entries and exits are also excluded from our measures of market mobility in order to ensure a measure that truly measures competition among incumbent firms. ${ }^{3}$ Third, the mobility rates are not computed annually, but refer to a longer term period. When new firms challenge incumbent firms to perform better, in theory they initiate a creative destruction process, where competitive entrants and incumbents survive and grow and inefficient firms exit or decline. However, this process does not materialise in a single year but rather takes a considerably longer period. ${ }^{4}$ Accordingly, the associated changes in firm rankings expressed by the mobility rate also do not

\footnotetext{
${ }^{3}$ There is also a practical reason. Firms with four or fewer workers form the vast majority of firms in any economy. Because we use fractile classes to classify the firms in terms of size, there would be too many firms with the same size to distribute the firms over the fractile classes (which by definition are equally large).

4 According to Verhoeven (2004) it takes 7-8 years before the productivity of a new-firm start-up in the Netherlands equals that of the average incumbent.
}

materialize from one year to the next. Therefore, mobility indices are computed over a longer period of time, in this case six years. Specifically, firm rankings in a given market (a region-sector unit, in this case) are compared between January 1st, 2000 and January 1st, 2006 (for firms existing on both dates). Fourth, the firms are ranked in four quartiles, based on employment size. ${ }^{5}$ Hence, a firm moves from one state to another when it moves from one quartile (e.g. the highest $25 \%$ of firms in terms of employment) to another. The size-based ranking in quartiles is computed at the regional and sector level, i.e. a transition matrix is constructed for each sector in each region based on all firms ( $>4$ workers) within that sector and region.

\section{Data and model}

The analysis assesses, at the region-sector level, the relationship between market mobility rates and startup rates and control variables. The regional dimension is at the NUTS-III spatial aggregation level, also known as the COROP classification. This implies there are 40 regions. Regarding sectors, the data allow for a five-sector classification (cf. Van Stel and Suddle 2008): manufacturing (International Standard Industrial Classification code D), construction (ISIC code F), trade (ISIC codes GH), transport and communication (ISIC code I), and services (ISIC codes JKNO). The empirical analysis is done at the region-sector level specified above. The following variables are included in the empirical analyses (descriptive statistics and/or regression analysis).

\subsection{Mobility rate 2000-2006}

This is the dependent variable. As described above, mobility rates are computed using data for those establishments which have five or more workers both in 2000 and in 2006. Firm entries and exits are excluded from this measure. Data on individual firms are taken from the data base REACH (REview and Analysis of Companies in Holland), which is operated by a private firm called Bureau van Dijk. The original source of these data is the so-called "Handelsregister"

${ }^{5}$ If 10 fractile classes are used, the number of observation per cell becomes too small. 
(trade record) maintained by the Dutch Chambers of Commerce. Initially, for each region mobility rates are computed at the sector level distinguishing 16 industries (cf. Folkeringa et al. 2011). Next, the mobility rates are aggregated towards the five-sector level described above using a sectoral weighting scheme. ${ }^{6}$

\subsection{Average start-up rate 1999-2005}

Following the labour market approach, the start-up rate is calculated as the number of new-firm start-ups divided by employment. The data on the number of start-ups are taken from the Dutch Chambers of Commerce. The number of start-ups is defined to include all independent new-firm registrations. It includes both new firms with employees and new firms without employees. Mergers, new subsidiary companies, new branches, and relocations to other regions are not counted as a start-up. Data on employment are taken from Statistics Netherlands and the employment figures relate to employee jobs expressed in full-time equivalents (labour years). ${ }^{7}$

\subsection{Average start-up rate 1993-1999}

As explained earlier, the effect of start-ups on mobility may be lagged. Therefore, the analyses include lagged start-up rates.

\subsection{Population density}

In more dense regions local competition may be stronger and this might positively affect mobility rates. Data for population density are taken from Statistics Netherlands.

\subsection{Average firm size 2000-2006}

In markets with larger firms (i.e. higher average firm size) firm movements between fractile classes may occur less often because they require bigger

\footnotetext{
${ }^{6}$ We aggregate towards the five-sector classification because the start-up rate variable is not available at lower sectoral aggregation levels.

7 Because of a change in the employment data at Statistics Netherlands, data for 2006 are not comparable with those for 2005. Therefore, we use the average of 1999-2005 instead of 2000-2006, the period for which we measure mobility.
}

investments to overtake other firms in the ranking. Stated differently, in scale-based industries market structure is generally less volatile. Average firm size is computed as employment (employee jobs expressed in full-time equivalents) divided by the number of firms. Data sources are Statistics Netherlands and the Dutch Chambers of Commerce, respectively.

\section{Descriptive statistics}

\subsection{Regional differences in mobility rates}

Figure 1 illustrates market mobility rates by COROP region. In the map, the regions have been classified into quartiles of 10 regions. It seems that mobility is particularly high in the regions around Amsterdam/ The Hague and the area to the North of Amsterdam (i.e. large parts of the province "Noord-Holland"). Mobility is also high in Flevoland and parts of Zeeland in the South-west. Mobility is low in the North of the country (with Zuidoost Friesland as a notable exception, perhaps a result of the policy to focus growth around the A7 corridor-with Heerenveen as focus point-which runs through this region) and in Brabant and Limburg in the South. In interpreting Fig. 1, one should bear in mind that the regional patterns are to some extent affected by different sector structures across regions. ${ }^{8}$ As explained in the next subsection, mobility rates vary across sectors.

\subsection{Correlations between start-up rates and mobility rates}

Table 1 shows the correlations between start-up rates and mobility rates, by sector. In theory a higher startup rate fuels a creative destruction process which should be reflected in higher mobility rates. Hence, the correlation is expected to be positive. The results show important differences across industries: relatively large positive correlations are observed for manufacturing and construction (although only significant for manufacturing) whereas for trade, transport, and services the relationship is weak (correlation below or approximately 0.10 ). The table suggests that the relationship between start-ups and mobility varies by

$\overline{8}$ The sectoral mobility rates were weighted by sector employment to arrive at an aggregate regional mobility rate. 


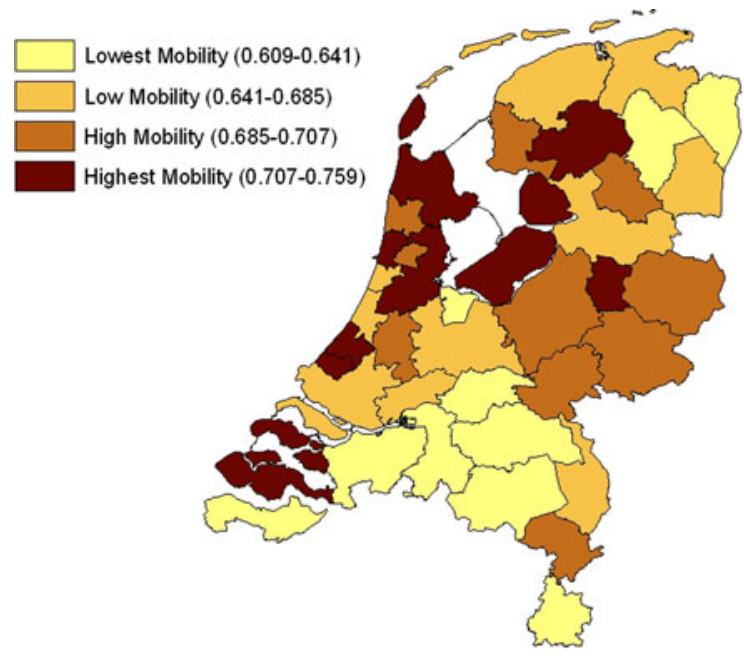

Fig. 1 Market mobility indices across regions (in quartiles)

sector. This is taken into account in the multivariate analysis.

\section{Regression analysis}

The multivariate analysis assesses the effect of startup rates on market mobility while controlling for other explanatory factors. From the theoretical framework it is expected that new firms challenge incumbent firms, which should lead to increased competition, reflected by higher mobility rates. This suggests a positive relationship between start-up rates and mobility. Because the lag with which this may occur is not known beforehand, several variations of the models are run accounting for both current and lagged start-up rates. In the models, population density is included as a catch-all variable that is strongly correlated with aspects such as educational attainment, income levels, and market access. Its expected effect is positive. Mobility rates are structurally different across sectors (Table 1 and Folkeringa et al. 2011). In order to correct for this, a set of sector dummies is included. Among other things, the sector dummies correct for the effect of different scales of operation across different sectors, possibly affecting market mobility (Table 1).

As the correlation table shows, the relationship between start-ups and mobility varies by sector. Therefore, the models should be run for each of the sectors separately. However, as this would result in quite small samples (40 observations per sector), the sectors manufacturing and construction are clustered into one group, labelled "Industry". The remaining three sectors are merged into a broad "Services" sector. This results in estimation samples of 80 and 120 observations, respectively. As mentioned before, in the estimation of the models sector dummies at the five-sector level are included.

Table 2 presents regression results for all five industries together, and Tables 3 and 4 deal with the separate results for Industry and Services, respectively. Each table has four model variants. The first variant includes the start-up rate and the control variable population density. The second variant adds sector dummies to the model. Variants three and four repeat variants one and two, the difference being that lagged start-up rates are used instead of current startup rates. In all model variants, outlier observations are excluded from the estimations (seven in total).

In the analysis for all industries together (Table 2), the control variable population density is consistently positive but insignificant except for the fourth model variant. Apparently, population density only weakly affects regional variations in market mobility. Comparing Models 1 and 2 on the one hand, and Models 3

Table 1 Correlations between start-up rates and mobility rates

\begin{tabular}{llcrrr}
\hline Correlation & Manufacturing & Construction & Trade & Transport & Services \\
\hline Start-up rate-mobility rate & $0.54 * * *$ & 0.22 & 0.10 & 0.02 & 0.12 \\
Lagged start-up rate-mobility rate & $0.49 * * *$ & 0.25 & -0.01 & -0.11 & 0.07 \\
Sample averages & & & & & \\
Average firm size 2000-2006 & 13.86 & 4.20 & 7.37 & 6.36 \\
Mobility rate 2000-2006 $(\times 100)$ & 55.71 & 68.88 & 71.50 & 64.52 & 71.00 \\
\hline
\end{tabular}

Note: Start-up rate relates to the period 1999-2005, lagged start-up rate relates to the period 1993-1999, mobility relates to the period 2000-2006. Each correlation is based on 40 observations (regions)

$* * * p<0.01 ; * * p<0.05 ; * p<0.10$ 
Table 2 Estimation results for all industries (total sample)

\begin{tabular}{lllll}
\hline Variable & I & II & III & IV \\
\hline Constant & $61.36(1.12)^{* * *}$ & $62.56(1.20)^{* * *}$ & $58.27(1.24)^{* * *}$ & $62.48(1.35)^{* * *}$ \\
Population density & $0.10(0.09)$ & $0.10(0.07)$ & $0.14(0.09)$ & $0.12(0.07)^{*}$ \\
Start-up rate (99-05) & $0.29(0.07)^{* * *}$ & $0.21(0.11)^{* *}$ & & \\
Lagged start-up rate (93-99) & & & $0.59(0.09)^{* * *}$ & $0.16(0.11)$ \\
Dummy manufacturing (D) & & $-8.19(1.33)^{* * *}$ & & $-8.16(1.38)^{* * *}$ \\
Dummy construction (F) & & $-3.68(2.35)$ & & $-1.02(1.52)$ \\
Dummy trade (GH) & & $5.60(1.43)^{* * *}$ & & $5.82(1.46)^{* * *}$ \\
Dummy transport (I) & - & & - \\
Dummy bus. services (JKNO) & & $5.05(1.45)^{* * *}$ & & $5.98(1.32)^{* * *}$ \\
$R$-squared & 0.10 & 0.53 & 0.20 & 0.52 \\
Adjusted $R$-squared & 0.09 & 0.51 & 0.19 & 0.51 \\
Log likelihood & -664.01 & -602.01 & -653.29 & -602.82 \\
$N$ & 193 & 193 & 193 & 193 \\
\hline
\end{tabular}

Note: Pooled OLS regressions for all industries (outliers excluded), standard errors in parentheses

Dependent variable: mobility rate

$* * * p<0.01 ; * * p<0.05 ; * p<0.10$

Table 3 Estimation results for industry (manufacturing + construction)

\begin{tabular}{lllll}
\hline Variable & I & II & III & IV \\
\hline Constant & $54.76(1.13)^{* * *}$ & $59.15(3.15)^{* * *}$ & $53.81(1.21)^{* * *}$ & $58.64(2.61)^{* * *}$ \\
Population density & $0.01(0.10)$ & $0.06(0.11)$ & $0.03(0.10)$ & $0.07(0.10)$ \\
Start-up rate (99-05) & $0.38(0.05)^{* * *}$ & $0.21(0.13)^{*}$ & & \\
Lagged start-up rate (93-99) & & & $0.63(0.09)^{* * *}$ & $0.36(0.16)^{* *}$ \\
Dummy manufacturing & & $-4.53(3.04)$ & & $-4.74(2.28)^{* *}$ \\
Dummy construction & & - & & - \\
$R$-squared & 0.43 & 0.44 & 0.43 & 0.46 \\
Adjusted $R$-squared & 0.41 & 0.42 & 0.41 & 0.44 \\
Log likelihood & -242.49 & -241.33 & -242.31 & -240.10 \\
$N$ & 78 & 78 & 78 & 78 \\
\hline
\end{tabular}

Note: Pooled OLS regressions for Industry sectors (outliers excluded), standard errors in parentheses

Dependent variable: mobility rate

$* * * p<0.01 ; * * p<0.05 ; * p<0.10$

and 4 on the other hand, it is clear that the $\log$ likelihood value increases substantially. Indeed, likelihood ratio tests confirm that the model fit is increased significantly by including the sector dummies. This confirms the idea that sector differences are an important element in the relationship between start-ups and derived competition. Models 2 and 4 are therefore the preferred models and it is clear that the effect of the current start-up rate is significantly positive (Model 2). However, the effect of the lagged start-up rate is not significantly different from zero, suggesting the positive effect emerges relatively quickly. The effects vary by sector though.

Table 3 presents the results for "Industries" and it is clear that the effect of start-ups on market mobility is positive and highly significant in all variants, suggesting fierce competition between new and incumbent firms. Likelihood ratio values do not increase much as a result of including the sector dummy and, according to statistical tests, Model 2 
Table 4 Estimation results for services (trade + transport + business services)

\begin{tabular}{lllll}
\hline Variable & I & II & III & IV \\
\hline Constant & $59.64(1.83)^{* * *}$ & $61.95(1.98)^{* * *}$ & $63.67(1.85)^{* * *}$ & $63.75(1.80)^{* * *}$ \\
Population density & $0.21(0.10)^{* *}$ & $0.14(0.10)$ & $0.20(0.11)^{* *}$ & $0.11(0.10)$ \\
Start-up rate (99-05) & $0.76(0.14)^{* * *}$ & $0.29(0.23)$ & & \\
Lagged start-up rate (93-99) & & & $0.36(0.13)^{* * *}$ & $0.02(0.15)$ \\
Dummy trade & & $5.10(1.93)^{* * *}$ & & $6.77(1.65)^{* * *}$ \\
Dummy transport & & - & & - \\
Dummy business services & 0.21 & $4.55(1.97)^{* *}$ & & $6.34(1.38)^{* * *}$ \\
$R$-squared & 0.20 & 0.26 & 0.08 & 0.25 \\
Adjusted $R$-squared & -364.04 & 0.23 & 0.06 & 0.22 \\
Log likelihood & 115 & -360.42 & -372.80 & -361.24 \\
$N$ & 115 & 115 & 115 \\
\hline
\end{tabular}

Note: Pooled OLS regressions for Services sectors (outliers excluded), standard errors in parentheses

Dependent variable: mobility rate

$* * * p<0.01 ; * * p<0.05 ; * p<0.10$

does not outperform Model 1. On the other hand, Model 4 does outperform Model 3. As Models 1 and 4 are thus the preferred models, the coefficient for the start-up rate is about 0.35 . The similar magnitude for the current and lagged start-up rates suggests that the actual lag is somewhere in between 1 and 7 years. It takes some time before new firms actually challenge incumbent firms.

In Table 4 results for Services sectors (trade, transport, and business services) are presented. In Models 1 and 3, the effect of the start-up rate is positive and highly significant. However, these results are driven by sector differences between trade, transport, and business services, and merely reflect differences in mobility rates across these sectors. When controlled for sector dummies the effect disappears. There is no evidence of a relationship between start-ups and mobility for services sectors.

The insignificant effect for services is contrary to expectations, but the combined picture with the estimated large effects for industry seems to be consistent with earlier findings. There are three possible explanations of the different results between the sectors. First, Van Stel and Suddle (2008) find that, compared with other sectors, the effect of new firm formation on regional economic development is by far the largest for start-ups in manufacturing. The authors argue that differences in innovation characteristics between manufacturing industries and services industries are an important discriminating factor. Innovations in services industries are often non-technological and mostly involve small and incremental changes in processes and procedures, whereas innovations in manufacturing may have a greater effect because they tend to require more $R \& D$ and are often more radical in nature. New firms performing innovative activities may therefore be more of a threat to incumbent firms in manufacturing industries compared with services industries. Hence, in manufacturing, incumbent firms are actually challenged by (innovative) newcomers so they also are forced to perform better. This increases competition among incumbent firms, which is reflected by higher market mobility levels (and hence a significant relationship between start-ups and mobility).

A second argument is that entry barriers may cause a selection effect among potential entrants. It is wellknown that entry barriers in manufacturing sectors are more apparent than in services sectors. Entry may be deterred by forcing the entrant to come in on a large scale and with high risk, or to come in on a small scale at a cost disadvantage (economies of scale). Entry may also be deterred by the fact that established firms have brand identification and consumer loyalty (product differentiation), and the need to invest large amounts of capital in order to compete, particularly if the capital is required for risky or unrecoverable up-front advertising or R\&D (capital requirements). These entry barriers are related to the uncertainty of entrants' investments and have 
consequences for the number of entrants and the commitments they choose (Caves 1998). The large investment requirements for setting up a business in Industry sectors (particularly manufacturing) and the uncertain rewards impose a relatively high barrier. Therefore, gross entry tends to be lower for industry sectors than for services. However, as a result the average quality of entry might be higher for Industry sectors, given that a potential entrant thinks twice about entering a market with such high entry barriers. Yip (1982) argues that "gateways to entry" might exist through the unique set of skills, resources, and networks possessed by potential entrants. For markets with relatively high entry barriers it is more likely that entrants actually possess these qualities, whereas those who think they do not possess these qualities will not enter, because of the greater risks involved. In contrast, in large parts of the services sector, start-up costs are relatively low and therefore the potential loss of investment costs is much lower, enabling many potential entrants (even low-quality entrants) to "try their luck". As a result of the high-quality entry in Industry sectors, incumbent firms are more heavily challenged by the entrants, which increases competition and drives mobility rates upwards.

Third, in the Netherlands there is a trend that many solo self-employed (entrepreneurs owning businesses without employees) enter the labour market. These individuals start businesses not because they intend to grow their business but because they prefer the freedom of working autonomously, instead of working as an employee where they have to answer to managers. Typically, these entrepreneurs enter in services sectors where entry barriers are low. In recent decades, increased differentiation of consumer services, declining transaction costs, and increasing network economies related to information technology have made it possible for these entrepreneurs to maintain viable firms on a very small scale (Wennekers et al. 2010). However, as these entrepreneurs do not have the intention to grow their business, they are also not really challenging incumbent firms, consistent with a lack of significant relationship between start-ups and mobility rates in services. The phenomenon of the solo self-employed is almost non-existent in manufacturing, because working without employees implies operating far below the minimum efficient scale.

\section{Conclusions}

This study investigated the effect of start-up rates on a measure of competition between incumbent firms called market mobility. Based on Joseph Schumpeter's theory of creative destruction, many researchers hypothesize that start-ups lead to increased levels of competition. New firms challenge existing firms by introducing new products and services and market selection will cause the best firms to survive and grow and the least competitive firms to downsize or exit. This study directly tested this hypothesis by assessing the relationship between start-up rates and a measure of competition. This was done by establishing a regression model at the region-sector level for the Netherlands. Using data for 40 regions and five sectors over the period 1993-2006 the effect of start-ups on market mobility is found to vary by sector. There is a strong positive effect for manufacturing and construction. For service sectors, the relationship is insignificant.

The results suggest there are differences in the types of entry between sectors and in the roles start-ups play in these sectors. Possibly, manufacturing start-ups enter because of perceived business opportunities based on innovations and precise estimates of their resources and their probability of success. Entry barriers may cause a selection effect and result in a higher average quality of new-firm start-ups relative to other sectors. By competing on innovation, start-ups stimulate competition between incumbents resulting in higher mobility rates. In the services sector, by contrast, start-ups may be followers reacting to growing markets. Start-ups would then increase the scope of markets, but do not increase competition as such. One may argue that a manifestation of this increased scope is the emergence of a large group of solo self-employed in the Netherlands. In addition, start-ups could improve general local economic conditions from which incumbents firms can also benefit. In this case, start-ups will not lead to competition effects but rather to an overall improvement of the local economy. It is likely that this improvement would be sector-specific, which could account for the sector differences found. These ideas suggest that future research should focus on computing market mobility rates at lower sectoral aggregation levels so that the relationship between start-up rates and mobility rates can be investigated for more narrowly defined markets. 
Acknowledgments We are grateful to participants at the international workshop on "Entrepreneurial Activity and Regional Competitiveness" (San Sebastian, June 18-19, 2009), for providing us with helpful comments and suggestions. In particular, we would like to thank Joana Mendonça. The paper has been written in the framework of the research program SCALES carried out by EIM and financed by the Dutch Ministry of Economic Affairs.

Open Access This article is distributed under the terms of the Creative Commons Attribution Noncommercial License which permits any noncommercial use, distribution, and reproduction in any medium, provided the original author(s) and source are credited.

\section{References}

Acs, Z. J., \& Storey, D. J. (2004). Introduction: Entrepreneurship and economic development. Regional Studies, 38, 871-877.

Audretsch, D. B., \& Thurik, A. R. (2001). What is new about the new economy: Sources of growth in the managed and entrepreneurial economies. Industrial and Corporate Change, 19, 795-821.

Audretsch, D. B., \& Thurik, A. R. (2004). A model of the entrepreneurial economy. International Journal of Entrepreneurship Education, 2, 143-166.

Baldwin, J. R. (1995). The dynamics of industrial competition. Cambridge, UK: Cambridge University Press.

Baldwin, J. R., \& Gorecki, P. (1994). Concentration and mobility statistics in Canada's manufacturing sector. Journal of Industrial Economics, 42, 93-103.

Boeri, T., \& Cramer, U. (1992). Employment growth, incumbents and entrants: Evidence from Germany. International Journal of Industrial Organisation, 10, 545-565.

Bosma, N., Stam, E. \& Schutjens, V. (2011). Creative destruction and regional productivity growth: Evidence from the Dutch manufacturing and services industries, Small Business Economics (forthcoming). Available online.

Cantner, U., \& Krüger, J. J. (2004). Geroski's stylized facts and mobility of large German manufacturing firms. Review of Industrial Organization, 24, 267-283.

Caves, R. E. (1998). Industrial organization and new findings on the turnover and mobility of firms. Journal of Economic Literature, 36, 1947-1982.

Deutsch, J., \& Silber, J. (1995). Static versus dynamic measures of aggregate concentration: The case of Fortune's 500. Southern Economic Journal, 62, 192-209.
Folkeringa, M., Van Stel, A., Suddle, K., \& Tan, S. (2011). Measuring business dynamics among incumbent firms in The Netherlands. International Journal of Entrepreneurship and Small Business, 12(2), 185-206.

Fritsch, M. (2008). How does new business formation affect regional development? Introduction to the special issue. Small Business Economics, 30, 1-14.

Fritsch, M., \& Mueller, P. (2004). Effects of new business formation on regional development over time. Regional Studies, 38, 961-975.

Fritsch, M., Noseleit, F., \& Schindele, Y. (2010). The direct and indirect effects of new businesses on regional employment: An empirical analysis. International Journal of Entrepreneurship and Small Business, 10(1), 49-64.

Geweke, J., Marshall, R. C., \& Zarkin, G. A. (1986). Mobility indices in continuous time Markov chains. Econometrica, 54, 1407-1423.

Kaminarides, J., \& Farahbod, K. (1995). Recent trends in concentration, mobility and turnover among the top US companies. International Advances in Economic Research, 1, 142-148.

Kato, M., \& Honjo, Y. (2006). Market share instability and the dynamics of competition: A panel data analysis of Japanese manufacturing industries. Review of Industrial Organization, 28, 165-182.

Norris, J. R. (1998). Markov Chains. Cambridge, UK: Cambridge University Press.

Shorrocks, A. F. (1978). The measurement of mobility. Econometrica, 46, 1013-1024.

Stonebraker, R. J. (1979). Turnover and mobility among the 100 largest firms: An update. American Economic Review, 69, 968-973.

Van Stel, A. J., \& Storey, D. J. (2004). The link between firm births and job creation: Is there a Upas Tree effect? Regional Studies, 38, 893-909.

Van Stel, A. J., \& Suddle, K. (2008). The impact of new firm formation on regional development in The Netherlands. Small Business Economics, 30, 31-47.

Verhoeven, W. H. J. (2004). Firm dynamics and labour productivity. In G. Gelauff, L. Klomp, S. Raes, \& T. Roelandt (Eds.), Fostering productivity: patterns, determinants and policy implications (pp. 213-241). Amsterdam: Elsevier BV.

Wennekers, S., Van Stel, A., Carree, M., \& Thurik, R. (2010). The relationship between entrepreneurship and economic development: Is it U-shaped? Foundations and Trends in Entrepreneurship, 6(3), 167-237.

Yip, G. S. (1982). Barriers to entry: A corporate-strategy perspective. Lexington, MA: Lexington Books. 